\title{
PEMANFAATAN AUGMENTED REALITY PADA MEDIA PEMBELAJARAN SEJARAH TENTANG BENDA-BENDA BERSEJARAH PENINGGALAN KERAJAAN MAJAPAHIT DI TROWULAN MOJOKERTO
}

\author{
Uliontang ${ }^{1}$, Endang Setyati $^{2}$, Francisca Haryanti Chandra ${ }^{3}$ \\ Teknologi Informasi, Fakultas Teknik \\ Institut Sains dan Teknologi Terpadu, Surabaya, Indonesia \\ e-mail: ${ }^{1}$ uliyontang@gmail.co.id, ${ }^{2}$ endang@stts.edu, ${ }^{3}$ fhc@stts.edu \\ Diterima: 24 April 2020. Disetujui : 20 Juni 2020. Dipublikasikan : 30 Juni 2020 \\ (C)2020 -TESJ Fakultas Teknik Universitas Maarif Hasyim Latif. Ini adalah artikel dengan \\ akses terbuka di bawah lisensi CC BY 4.0 (https://creativecommons.org/licenses/by/4.0/)
}

\begin{abstract}
ABSTRAK
Sistem pembelajaran di sekolah saat ini pada umumnya masih menggunakan buku dan alat peraga tradisional sebagai media pembelajaran dalam kelas. Hasil pembelajaran pada mata pelajaran sejarah, khususnya tentang benda-benda bersejarah yang mengindikasikan masih rendah hasil belajar dan motivasi belajar peserta didik. Maka diperlukan media pembelajaran yang dapat membantu pembelajaran, dari penelitian ini peneliti berusaha mengatasi masalah tersebut dengan mengembangkan media pembelajaran berupa aplikasi dengan memanfaatkan teknologi augmented reality yang berbasis android untuk mensimulasikan gambar benda 3D. Sistem kerja Augmented Reality menggunakan marker based tracking. Dengan menggunakan software 3d Max dan plug-in Vuforia. Pembuatan media pembelajaran dengan teknologi Augmented Reality dengan menggunakan Modality Principle. Peserta partisipan yang direkrut adalah peserta didik kelas XI SMA Wachid Hasyim 2 Sidoarjo. Penelitian ini menggunakan penelitian eksperimen, diawali dengan tes awal (pretest), kemudian diberikan perlakukan (treatment) dan diakhiri dengan sebuah tes akhir (posttest) yang akan diberikan kelas eksperimen dan kelas kontrol. Pada hasil penelitian menunjukkan tidak ada perbedaan yang signifikan antara hasil belajar pre-test antara kelompok kontrol dan kelompok eksperimen. Selanjutnya dari hasil post-test menunjukkan ada peningkatan hasil belajar peserta didik dan motivasi belajar pada proses belajar, ada perbedaan yang signifikan antara kelompok kontrol dan kelompok eksperimen. Kelompok eksperimen lebih tinggi secara signifikan dalam motivasi belajar dibandingkan dengan hasil belajar pada kelompok kontrol. Dari observasi dan wawancara yang didapat peserta didik lebih aktif pada kegiatan pembelajaran dan peserta didik bersemangat untuk mengikuti pembelajaran. Hal ini membuktikan bahwa peserta didik tertarik pada media ini yang bisa membangkitkan motivasi belajar.
\end{abstract}

Kata kunci : augmented reality, sejarah, benda sejarah, majapahit, media pembelajaran, benda $3 \mathrm{~d}$

\section{PENDAHULUAN}

Saat ini sistem pendidikan di sekolah dalam menyampaikan materi sudah melakukan berbagai macam metode dengan tujuan agar siswa tidak merasa bosan sehingga dalam menerima dan menyerap materi bisa semaksimal mungkin, dalam setiap peyampaian metode pembelajaran ada yang efektif ada juga yang kurang efektif salah satunya dengan cara mengajar tradisional yang dianggap kurang efektif dan mengurangi minat siswa, untuk itu dipandang perlu menggunakan metode yang memanfaatkan teknologi canggih saat ini.

Di SMA materi pembelajaran sejarah saat ini masih menggunakan cara konvensional dengan menggunakan buku referensi yang gambarnya masih 2D untuk itu dipandang perlu adanya perubahan dari gambar 2D menjadi 3D sehingga gambar terlihat lebih nyata dengan harapan bisa diterima dengan baik dan maksimal.

Teknologi informasi dan komunikasi saat ini memberikan peluang besar dalam penyampaian pembelajaran menjadi lebih efektif dan menarik dengan memanfaatkan augmented reality.

\section{METODE PENELITIAN}

\section{Desain Aplikasi Media Pembelajaran}

Penelitian ini bertujuan untuk mendesain media pembelajaran interaktif menggunakan augmented reality pada mata pelajaran sejarah benda-benda peninggalan Majapahit yang ada di museum Trowulan Mojokerto dan memberi kemudahan pengajar dalam pengajaran secara visual untuk transformasi ilmu dalam proses 
belajar mengajar. Sehingga pada saat diujicoba pada proses pembelajaran, media ini dapat memudahkan peserta didik untuk dapat memahami materi pembelajaran mata pelajaran sejarah serta tidak monoton dibanding dengan media pembelajaran yang tradisional.

Aplikasi media pembelajaran dirancang dengan memperhatikan proses informasi agar pesan yang disampaikan dalam media pembelajaran ini dapat diterima dan dicerna dengan mudah oleh peserta didik, seperti pada Gambar 1. Dengan menerapkan salah satu prinsip utama, bagaimana pemanfaatan media pembelajaran dapat membantu pembelajaran agar peserta didik bisa mengerti dan memahami materi.

Setelah proses pembuatan aplikasi selesai akan diujikan ke siswa dengan membagi 2 kelas yang terbagi dalam 1 kelas kontrol (konvensional) dan 1 kelas eksperimen (augmented reality) dengan melakukan pretest pada kelas kontrol dan eksperimen kemudian dilakukan uji aplikasi pada kelas eksperimen selanjutnya dilakukan postest pada kedua kelas tersebut seperti pada Gambar 2, untuk melihat hasil dari perlakuan yang berbeda.

\section{Penggunaan Augmented Reality dalam Media Pembelajaran}

Ronald T. Azuma (R. T. Azuma, 1997) mendefinisikan augmented reality adalah penggabungan benda-benda nyata dan maya di lingkungan nyata, yang berjalan secara interaktif dalam waktu nyata, dan terdapat integrasi antar benda dalam tiga dimensi, yaitu benda maya yang terintegrasi dalam dunia nyata. Penggabungan

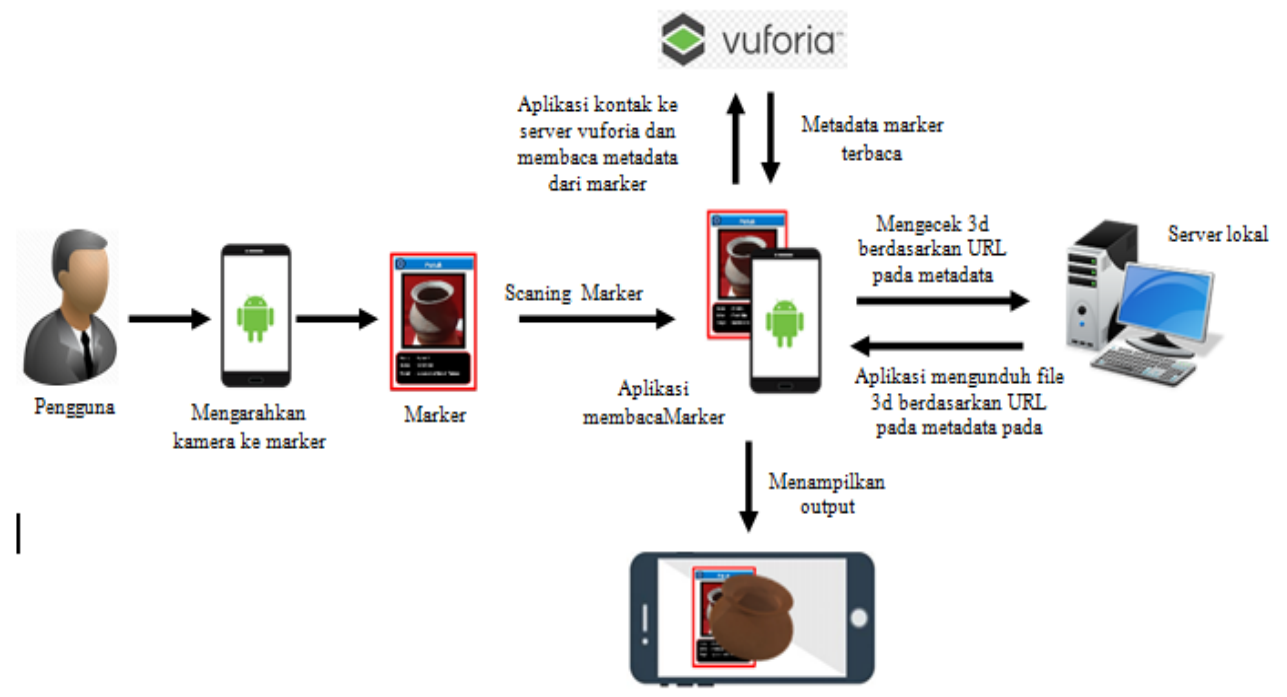

Gambar 1. Alur sistem aplikasi

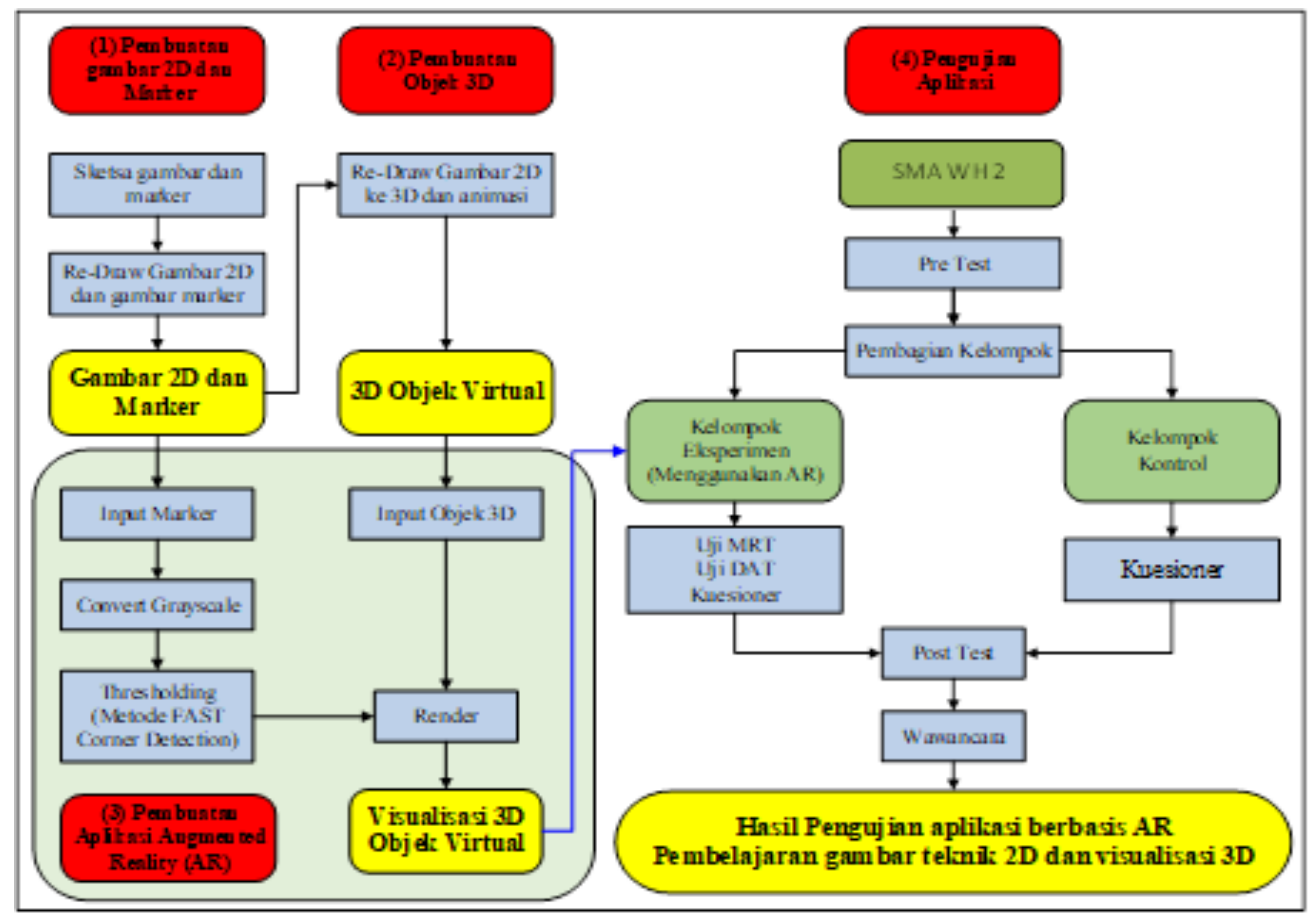

Gambar 2. Desain Arsitektur Penelitian Pembelajaran 
antara nyata dan maya dengan teknologi dimungkinkan bisa mendapatkan tampilan yang sesuai, interaktivitas dimungkinkan dapat melalui perangkat-perangkat input tertentu, dan integrasi yang baik memerlukan penjejakan yang efektif.

Ada beberapa aplikasi yang dibutuhkan untuk bisa membuat sebuah augmented reality (AR) yang semuanya saling berinteraksi dalam mendukung tampilan yang sempurna, aplikasi yang dibutuhkan antara lain:

1. Unity

Unity merupakan game engine yang digunakan dalam pembuatan aplikasi. Unity merupakan suatu aplikasi yang digunakan untuk mengembangkan game multiplatform yang didesain untuk mudah digunakan. Unity penuh perpaduan dengan aplikasi yang profesional. Editor pada Unity dibuat degan user interface yang sederhana. Unity mendukung semua format file, terutama format umum seperti semua format dari art applications. Unity cocok dengan versi 64-bit dan dapat beroperasi pada Mac OS X dan Windows dan dapat menghasilkan game untuk Mac, Windows dan Android. Yang dilengkapi dengan plugin Vuforia sehingga dapat digunakan untuk membuat sebuah aplikasi dengan teknologi Augmented Reality. File *.exe Unity ini dapat diunduh di website Unity.

2. Vuforia

Vuforia adalah Augmented Reality Software Development Kit (SDK) yang digunakan dalam perangkat mobile yang memungkinkan dalam pembuatan aplikasi AR. SDK Vuforia juga tersedia untuk digabungkan dengan unity yaitu bernama Vuforia AR Extension for Unity. Vuforia merupakan SDK yang diproduksi oleh Qualcomm dengan tujuan untuk membantu para developer dalam membuat aplikasi-aplikasi AR di mobile phones (iOS, Android). SDK Vuforia berhasil dipakai di beberapa aplikasi-aplikasi mobile.

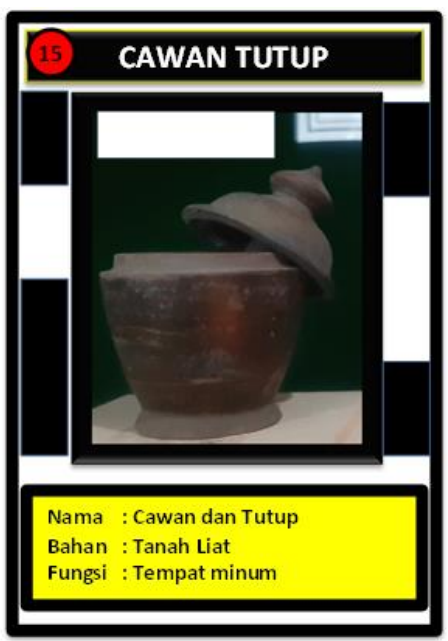

(a) Marker Cawan Tutup

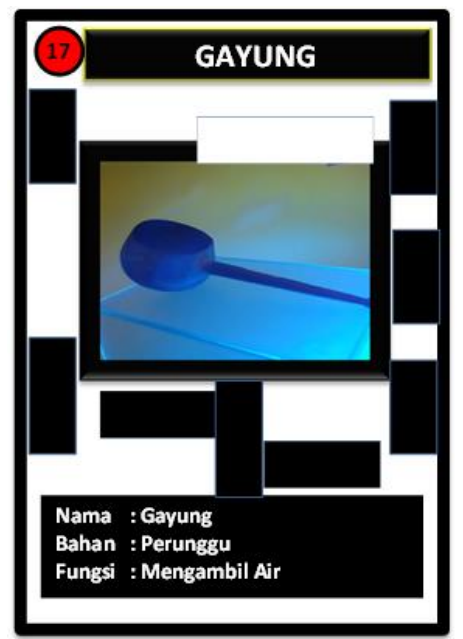

(b) Marker Gayung
Augmented Reality Vuforia ini memberikan cara berinteraksi yang memanfaatkan kamera mobile phones yang digunakan sebagai perangkat masukan (input), yang berfungsi sebagai perekam yang dapat mengenali penanda tertentu yang disebut dengan marker, dengan demikian pada layar bisa menampilkan perpaduan antara dunia nyata dan dunia yang dihasilkan oleh aplikasi. Sehingga dapat disimpulkan, Vuforia merupakan SDK untuk computer vision based augmented reality.

3. Microsoft Visual Studio

Microsoft Visual Studio merupakan sebuah perangkat lunak dengan fitur lengkap (suite) yang dapat dimanfaatkan sebagai pengembangan dalam aplikasi, antara lain aplikasi bisnis ataupun aplikasi personal, dalam bentuk aplikasi console, aplikasi Windows, ataupun aplikasi Web. Visual Studio mencakup compiler SDK, Integrated Development Environment (IDE), dan dokumentasi (umumnya berupa MSDN Library). Ada beberapa compiler yang dapat dimasukkan ke dalam paket Visual Studio yaitu Visual C++, Visual C\#, Visual Basic dan sebagainya.

Dalam Microsoft Visual Studio ini dapat digunakan untuk mengembangkan aplikasi dalam native code (pemrograman bahasa mesin yang berjalan di platform Windows) ataupun managed code (dalam bentuk Microsoft Intermediate Language di atas .NET Framework.

Setiap project Augmented Reality dibutuhkan sebuah marker. Marker yang digunakan pada aplikasi ini merupakan marker based tracking. Gambar yang akan dijadikan marker pada aplikasi ini didaftarkan ke Vuforia Developer terlebih dahulu supaya dapat dikenali sebagai marker pada unity.

Adapun beberapa marker yang digunakan dalam aplikasi unity antara lain marker cawan tutup seperti pada Gambar 3a marker cawan tutup

Gambar 3. Beberapa Marker yang Digunakan dalam Aplikasi Unity

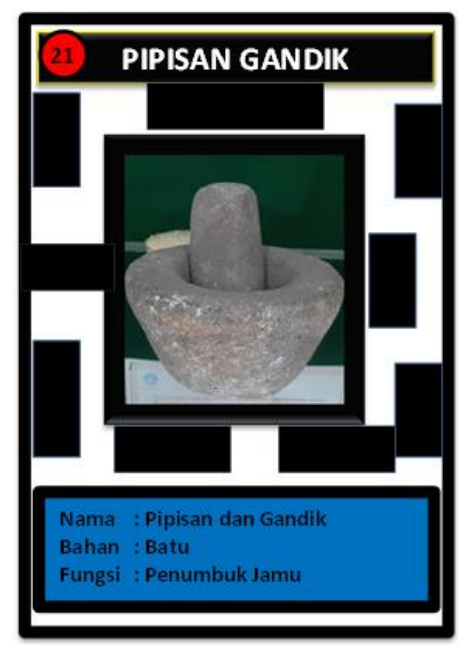

(c) Marker Pipisan Gandik 


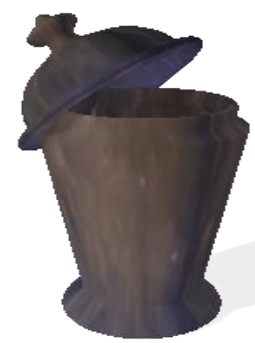

(a) cawan tutup

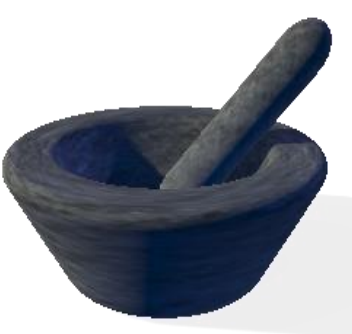

(b) pipisan dan gandik

Gambar 4. Objek 3D

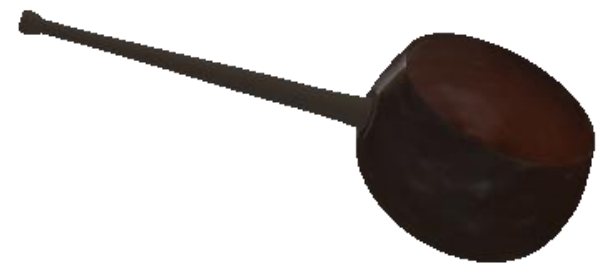

(c) gayung berfungsi untuk menampilkan gambar cawan tutup dalam bentuk 3D. Gambar 3b marker gayung marker ini berfungsi untuk menampilkan gambar gayung dalam bentuk 3D. Gambar 3c marker pipisan dan gandik marker ini berfungsi untuk menampilkan gambar pipisan dan gandik dalam bentuk 3D.

Sebagai tampilan objek output diperlukan aplikasi yang bisa mendesain gambar 3D sehingga bisa dikontrol secara maksimal dengan zoom dan rotasi, dalam penelitian ini penulis menggunakan 3Ds Max karena sudah memenuhi syarat untuk mendesain objek 3D, objek yang diambil sebagai output adalah benda-benda peninggalan sejarah Majapahit yang berada di Museum Trowulan Mojekerto objek dibuat semirip mungkin dengan benda aslinya, adapun objek 3D adalah cawan tutup seperti pada Gambar 4a, pipisan dan gandik pada Gambar 4b dan gayung pada Gambar 4c.

\section{Perancangan Antarmuka}

Interface atau antarmuka merupakan sebuah tampilan visual sebuah produk yang menjembatani sistem dengan pengguna (user). Tampilan UI dapat berupa bentuk, warna, dan tulisan yang didesain semenarik mungkin. Secara sederhana, UI (user interface) adalah bagaimana tampilan sebuah produk dilihat oleh pengguna dari suatu program aplikasi yang berperan sebagai media komunikasi yang digunakan sebagai sarana berdialog antara program dengan pengguna.

Tampilan awal aplikasi ini menampilkan menu atama yang terdiri dari 4 tombol yaitu : mulai, info aplikasi, bantuan dan keluar, seperti pada Gambar 5, dengan background candi yang terkesan sebagai bangunan pada jaman Kerajaan Majapahit. Adapun fungsi tombol-tombol tersebut antara lain :

a. Mulai : tombol ini berfungsi untuk masuk ke scan kamera yaitu mengscan marker untuk menampilkan objek 3D, dimana marker yang discan akan memunculkan benda 3D secara virtual dalam layar. Seperti pada Gambar 9, 10 dan 11.

b. Info : tombol ini berisikan informasi tentang seputar aplikasi benda sejarah Majapahit, seperti pada Gambar 6. Dalam layar informasi terdapat button materi untuk masuk ke tampilan materi yang berisi tentang sejarah Majapahit dan benda-benda peninggalan sejarah Majapahit, seperti pada Gambar 8.

c. Bantuan : tombol ini berisikan bantuan tentang tata cara penggunaan aplikasi seperti pada Gambar 7, pada tampilan bantuan terdapat button marker yang berfungsi sebagai link ke google drive untuk mendownload marker.

d. Keluar : tombol ini untuk keluar dari program

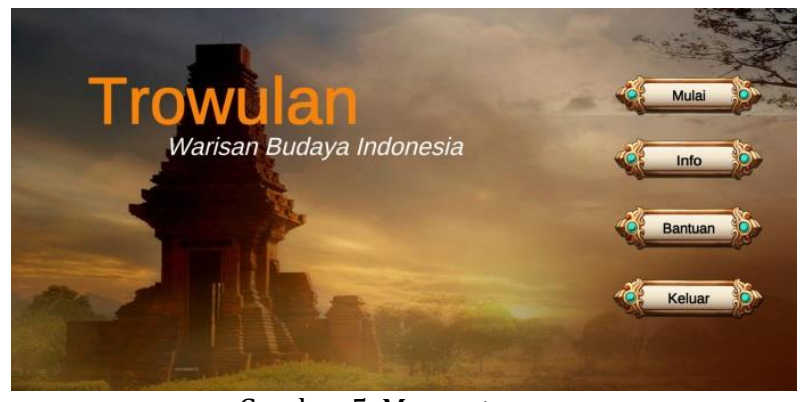

Gambar 5. Menu utama

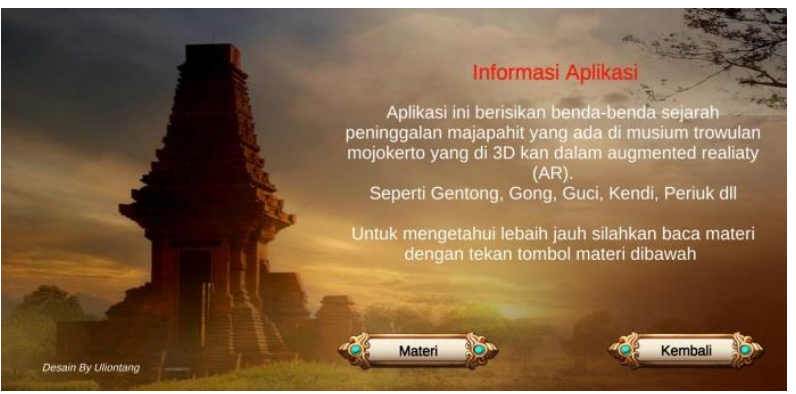

Gambar 6. Menu Informasi aplikasi

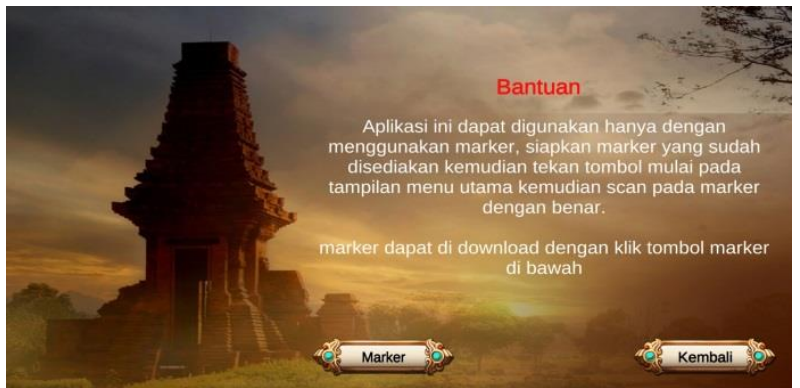

Gambar 7. Menu bantuan 


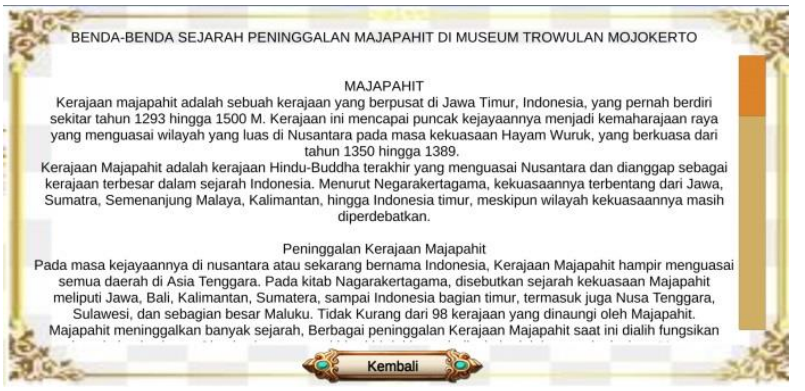

Gambar 8. Tampilan materi

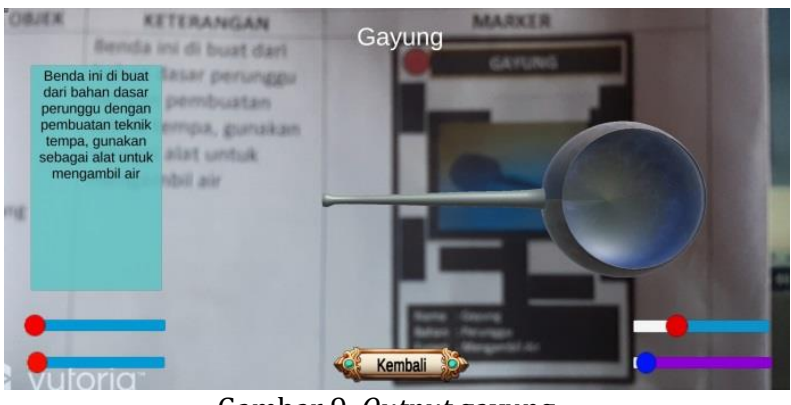

Gambar 9. Output gayung

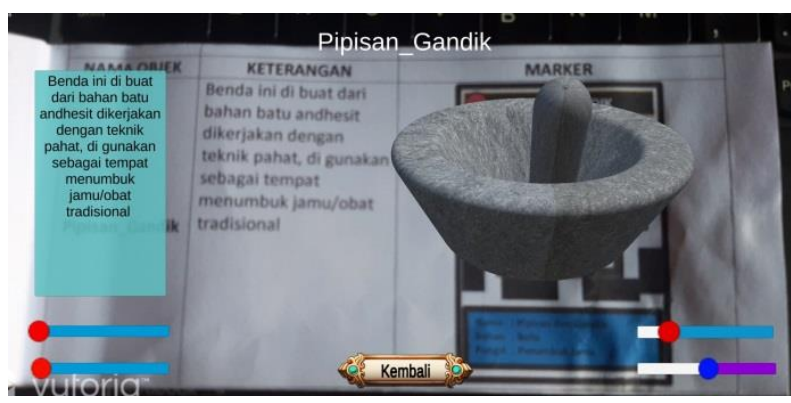

Gambar 10. Output pipisan dan gandik

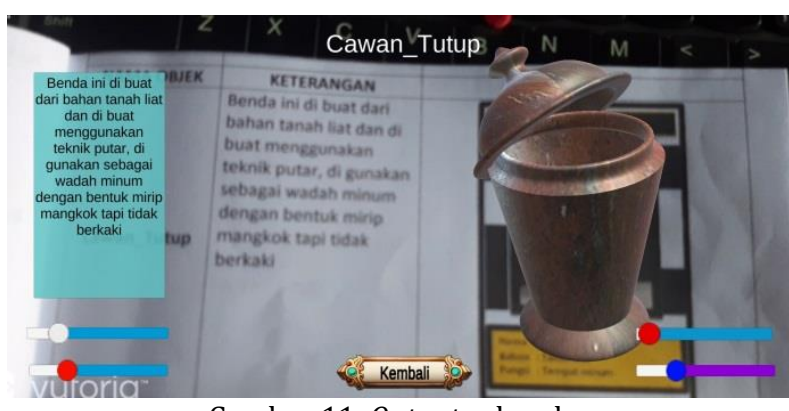

Gambar 11. Output celupak

Dibutuhkan sebuah output yang bersifat interaktif supaya dapat digunakan dengan mudah oleh user, untuk itu objek 3D yang muncul pada layar bisa dikontrol penuh seperti dengan zoom (perbesar dan perkecil) dan rotasi $360^{\circ}$ dengan sumbu $x, y$ dan $z$, dengan menggunakan slidebar seperti pada Gambar 9, 10, 11. Pada tampilan layar terdapat 4 (empat) slidebar yang masing-masing fungsinya berbeda, yaitu 1 slidebar untuk zoom dan 3 slidebar untuk rotasi $x, y$ dan $z$. Pada layar bagian atas terdapat teks nama objek yang berubah menyesuaikan nama benda yang muncul, kemudian pada layar sebelah kiri terdapat deskripsi teks dari objek yang isinya berubah menyesuaikan nama benda yang muncul. Output yang ditampilkan pada aplikasi ini gambar 3D yang berupa gayung seperti pada Gambar 9, pipisan dan gandik seperti pada Gambar 10, celupak seperti pada Gambar 11.

\section{HASIL DAN PEMBAHASAN}

Hasil penelitian dan pembahasan analisa data yang akan dijabarkan hasil analisis uji statistik dengan uji T menggunakan SPSS.

Dalam instrumen penelitian ini fasilitas yang digunakan oleh peneliti adalah mengumpulkan data. Instrumen yang valid berarti instrumen tersebut dapat mengukur apa yang hendak diukur. Pada penelitian ini instrumen yang digunakan adalah Instrumen tes dan Instrumen angket. Instrumen tes soal yang digunakan berupa objektif pilihan ganda yang terdiri dari 20 soal dari empat pilihan jawaban untuk mengukur hasil belajar peserta didik. Tes dilakukan sebelum (pre-test) dan sesudah (post-test) diberikan perlakuan. Terdapat pada Tabel 1 yang berisi kisi-kisi instrumen soal pre-test dan soal post-test.

Tabel 1. Kisi-kisi Instrumen Soal Pre-test dan Soal Post-test

\begin{tabular}{|c|c|c|c|}
\hline Konsep & Indikator Soal & $\begin{array}{l}\text { Nomor } \\
\text { Butir }\end{array}$ & $\begin{array}{c}\text { Jumlah } \\
\text { soal }\end{array}$ \\
\hline \multirow{5}{*}{$\begin{array}{l}\text { Benda sejarah } \\
\text { peninggalan } \\
\text { majapahit }\end{array}$} & $\begin{array}{l}\text { Pengertian benda } \\
\text { benda sejarah }\end{array}$ & 3,4 & 2 \\
\hline & $\begin{array}{l}\text { Mengenalkan benda- } \\
\text { benda sejarah } \\
\text { majapahit }\end{array}$ & $\begin{array}{l}1,2,9 \\
11,17 \\
19,7,8\end{array}$ & 8 \\
\hline & $\begin{array}{l}\text { Memahami bahan } \\
\text { dan teknik yang } \\
\text { digunakan dalam } \\
\text { pembuatan }\end{array}$ & $\begin{array}{l}5,6,10 \\
14\end{array}$ & 4 \\
\hline & $\begin{array}{l}\text { Memahami jenis- } \\
\text { jenis benda dan } \\
\text { fungsi benda } \\
\text { bersejarah }\end{array}$ & $\begin{array}{l}12,13 \\
15,16 \\
18,20\end{array}$ & 6 \\
\hline & \multicolumn{2}{|l|}{ Total } & 20 \\
\hline
\end{tabular}

Instrumen angket yang digunakan berupa skala likert. Skor jawaban ada lima alternatif jawaban. Skor jawaban dari lima alternatif tersebut bergerak dari skor tertinggi dan terendah untuk pernyataan yang menghendaki jawaban positif, Pengisian angket dilakukan selesai perlakuan.

Berdasarkan Tabel 2. hasil uji validitas menggunakan SPSS maka untuk $N=20$ yang terdiri dari 20 peserta didik dikelompok eksperimen dengan taraf signifikan berdasarkan tabel yaitu 5\% dan nilai $r_{\text {Tabel }}$ yang tercantum adalah 0,444 . Jika $r_{\text {Hitung }}$ lebih besar dari $r_{\text {Tabel }}$ maka dinyatakan valid dan jika $r_{\text {Hitung }}$ lebih kecil dari $r_{\text {Tabel }}$ maka dinyatakan tidak valid Dengan demikian di dapatkan pernyataan pada angket tersebut bahwa terdapat 8 valid dan 5 tidak valid. 
Tabel 2. uji validitas

\begin{tabular}{c|c|c}
\hline Indikator & Total $\left(\boldsymbol{r}_{\text {Hitung }}\right)$ & Keterangan \\
\hline 1 & 0,850 & Valid \\
\hline 2 & 0,239 & Tidak Valid \\
\hline 3 & 0,488 & Valid \\
\hline 4 & 0,744 & Valid \\
\hline 5 & 0,684 & Valid \\
\hline 6 & 0,632 & Valid \\
\hline 7 & 0,413 & Tidak Valid \\
\hline 8 & 0,552 & Valid \\
\hline 9 & 0,283 & Tidak Valid \\
\hline 10 & 0,868 & Valid \\
\hline 11 & 0,559 & Valid \\
\hline 12 & 0,358 & Tidak Valid \\
\hline 13 & $-0,050$ & Tidak Valid \\
\hline
\end{tabular}

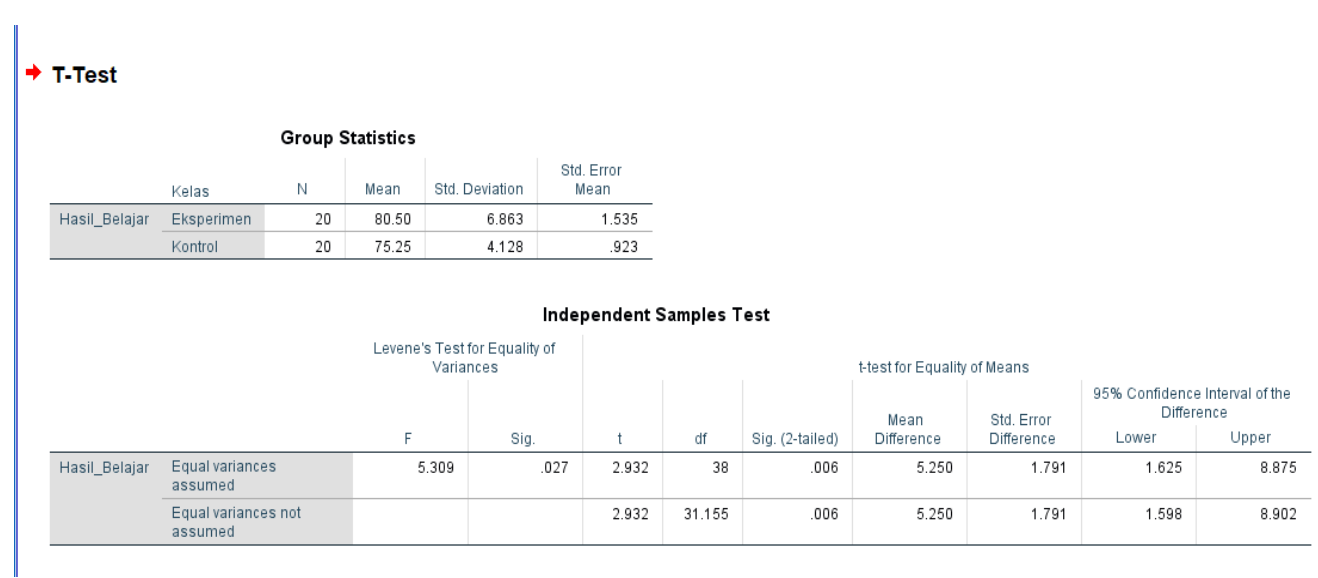

Gambar 12. Hasil uji T-Test

Berikutnya menguji reliabilitas yaitu suatu ukuran yang menunjukan sejauh mana hasil pengukuran tetap konsisten bila dilakukan pengukuran dua kali atau lebih terhadap gejala yang sama dengan alat pengukur yang sama pula. Pada penelitian ini menggunakan Cronbach Alpha. Uji Reliabilitas dapat dilakukan secara bersamasama terhadap seluruh butir pertanyaan. Menurut Sujarweni Wiratna (Sujarweni, 2015), jika nilai $\alpha>$ 0,60 butir pertanyaan tersebut reliabel.

Tabel 3. Tabel uji Reliabilitas

$$
\text { Reliability Statistics }
$$

Cronbach's Alpha $\mathrm{N}$ of Items

\begin{tabular}{r|r}
0.781 & 13 \\
\hline
\end{tabular}

Berdasarkan hasil uji reliabilitas Cronbach's Alpha pada tabel 3 menggunakan SPSS hasil nilai alpha 0,781 maka dinyatakan relibel karena nilai alpha lebih besar dari 0,60.

Berdasarkan hasil perhitungan statistik di atas, menampilkan bahwa kelas eksperimen memiliki mean (rata-rata) sebesar 80,50 dengan jumlah peserta didik 20 siswa. Kelas kontrol memiliki mean (rata-rata) sebesar 75,25 dengan jumlah peserta didik 20 siswa. Sedangkan berdasarkan tabel output Independent Sample Test
Nilai Sig.(2-tailed) sebesar 0,06. Hal tersebut mempunyai arti bahwa nilai Sig.(2-tailed) $<0,05$. maka sebagaimana dasar pengambilan keputusan dalam uji independent sample $t$ test dapat disimpulkan bahwa $\mathrm{H}_{\mathrm{o}}$ ditolak dan $\mathrm{H}_{\mathrm{a}}$ diterima, dimana Hipotesis nihil $\left(\mathrm{H}_{\mathrm{o}}\right)$ yaitu hipotesis yang menyatakan tidak ada hubungannya atau pengaruh antara variabel dengan variabel lain. Hipotesis alternatif $\left(\mathrm{H}_{\mathrm{a}}\right)$ adalah hipotesis yang menyatakan adanya hubungan atau pengaruh antara variabel dengan variabel lain.

\section{PENUTUP}

Dengan demikian dapat disimpulkan bahwa ada perbedaan hasil belajar yang signifikan dengan menggunakan media pembelajaran teknologi augmented reality yang mampu meningkatkan pemahaman siswa. Juga dapat membantu guru sebagai media pembelajaran dalam menyampaikan materi yang berbasis augmented reality, karena dapat dilihat dari sikap aktif siswa yang antusias dalam proses pembelajaran, karena merasa senang dan termotivasi. 


\section{DAFTAR PUSTAKA}

Anthony, M. (2007). Cognitive Development in 8- to 10-Year-Olds | Scholastic | Parents. Retrieved November 5, 2019, from https://www.scholastic.com/parents/family -life/creativity-and-criticalthinking/developmentmilestones/cognitive-development-8-10year-olds.html

Azuma, R., Baillot, Y., Behringer, R., Feiner, S., Julier, S., \& Macintyre, B. (2001). Recent advances in augmented reality. IEEE Computer Graphics and Applications, 21(6), 34-47.

Azuma, R. T. (1997). A survey of augmented reality. Presence: Teleoperators \& Virtual Environments, 6(4), 355-385.

Karamanoli, P., \& Tsinakos, A. (2016). A Mobile Augmented Reality Application for Primary School's History. IOSR Journal of Research \& Method in Education, 6(6), 56-65. Retrieved from www.iosrjournals.org

Miller, M. R., Jun, H., Herrera, F., Yu Villa, J., Welch, G., \& Bailenson, J. N. (2019). Social interaction in augmented reality. PloS One, 14(5), e0216290.

Rezende, W. J., Albuquerque, E. S., \& Ambrosio, A. P. (2017). Use of Augmented Reality to Support Education: Creating a Mobile E-learning Tool and using it with an Inquiry-based Approach. Proceedings of the 9th International Conference on Computer Supported Education (CSEDU 2017) - Volume 1 , 100-107. https://doi.org/10.5220/00063187010001 07

Sujarweni, V. W. (2015). SPSS untuk Penelitian. Yogyakarta: Pustaka Baru Press.

Zuono, T. T., Hatta, M., Kurniawan, C., Sugiarto, I., Anggraini, M., Purwadi, A., ... Souisa, F. (2019). Build design introduction to university profiles using the logo with the augmented reality method. Journal of Physics: Conference Series, 1175(1), 12115. IOP Publishing. 
Uliontang, dkk / Teknika : Engineering and Sains Journal, Vol. 4, No.1, Juni 2020, 19-26

halaman ini sengaja dikosongkan 